\title{
Introdução às justificativas clínicas e teóricas da hipótese das paixões "tóxicas"1
}

\author{
Introduction to clinical and theoretical justifications \\ regarding the "toxic" passions hypothesis
}

\author{
Victor Eduardo Silva BENTO2
}

\begin{abstract}
Resumo
Pesquisa de revisão crítica da literatura visando elucidar questões da experiência do autor com a clínica psicológica das paixões "tóxicas". Partiu-se da hipótese das paixões "tóxicas", isto é, de que existe uma analogia funcional entre as paixões e as toxicomanias devido à função do excesso narcísico, semelhante, mas não idêntica, em ambas. Mais precisamente, postulou-se que, do ponto de vista do inconsciente, seria o excesso narcísico que intoxicaria tanto nas paixões quanto nas toxicomanias. O objetivo foi justificar esta hipótese. O plano de trabalho foi: 1) relatar e questionar a história da experiência profissional do autor, para tratar das justificativas clínicas; 2) abordar os fundamentos teóricos desta história para discutir as justificativas teóricas. Destacaram-se as teorizações de Olievenstein sobre o estádio do espelho partido, de Delrieu sobre a história da toxicomania na França e de Le Poulichet sobre toxicomanias, operação do phármakon e psicanálise.
\end{abstract}

Unitermos: Narcisismo. Psicanálise. Toxicomanias.

\begin{abstract}
We have conducted a search of critical reviews of the literature to elucidate questions arising from the author's experience with the psychological clinicfor "toxic" passions. We started from the "toxic" passions hypothesis, according to which a functional analogy exists between passions and toxicomanias: the function of narcissistic excess, similar, but not identical, in both. To be more precise, we proposed the hypothesis that, from the unconscious point of view, the excess narcissism would intoxicate both in passions and in toxicomanias. The objective was to justify this hypothesis. The plan for this study was: 1) To report and to question the history of the author's professional experience, to deal with the clinical justifications; and 2) To discuss the theoretical basis of this history, to discuss the theoretical justifications. We have highlighted Olievenstein's theorizations about the broken mirror stage, Delrieu's assumptions about the history of toxicomanias in France and Le Poulichet's formulations about "toxicomanias, farmakon operation and psychoanalysis".
\end{abstract}

Uniterms: Toxicomania. Narcissism. Psychoanalysis.

Realizou-se uma pesquisa de revisão crítica da literatura visando elucidar questões da experiência profissional do autor com a clínica psicológica das paixões"tóxicas". Como seu título sugere, parte-se neste trabalho do pressuposto hipotético das paixões"tóxicas", isto é, de que as paixões são semelhantes, porém não

\section{$\nabla \nabla \nabla \nabla$}

1 Artigo elaborado a partir da tese não-publicada de V.E.S. BENTO, intitulada "La passion amoureuse 'toxique': une approche psychanalytique à partir de la sémiologie et du narcissisme chez Freud". Universidade de Paris 7, 1996.

2 Universidade Federal do Rio de Janeiro, Centro de Filosofia e Ciência Humanas, Instituto de Psicologia, Departamento de Psicometria. Av. Pasteur, 250, Pavilhão Nilton Campus, Praia Vermelha, 22290-240, Rio de Janeiro, RJ, Brasil.E-mails: <vsilvabento@yahoo.com.br>; <victorbento@oi.com.br>. 
idênticas, às toxicomanias. Postula-se, então, a existência de uma analogia funcional entre as paixões e as toxicomanias. O título também sugere o objetivo deste artigo: introduzir as justificativas clínicas e teóricas desta hipótese das paixões "tóxicas". Para atingir este objetivo, o plano deste trabalho implicou uma dupla empreitada: 1) relatar e questionar a história da experiência profissional do autor com a clínica psicológica das paixões "tóxicas", ao longo de três tempos principais (de 1/1978 a 2/1984; de 2/1984 a 6/1991 e a partir de 7/1991); e 2) abordar os fundamentos teóricos que embasaram cada um destes três momentos. Acredita-se que com esta dupla ação foi possível demonstrar como se chegou à hipótese em questão e, assim, justificá-la com argumentos clínicos e teóricos.

\section{$1{ }^{\circ}$ tempo}

A experiência profissional do autor começou no campo da psicologia clínica, em janeiro de 1978, com um estágio realizado no Serviço de Liberdade Assistida (SLA) do Juizado de Menores do Rio de Janeiro, estágio este que se estendeu até fevereiro de 1984. Neste primeiro tempo da experiência profissional do autor relacionada à hipótese das paixões "tóxicas" e à sua clínica, esta hipótese em sua expressão final - que faz referência à existência de uma analogia funcional entre as paixões e as toxicomanias - ainda não existia; estava, portanto, em seu momento latente de concepção e gestação.

Dentre as atividades principais deste estágio podem-se destacar o psicodiagnóstico e a psicoterapia de orientação psicanalítica de adolescentes usuários de drogas. Estes eram encaminhados pelo juiz de menores ao SLA para que sua equipe multidisciplinar, constituída principalmente por psicólogos e estagiários de psicologia, realizasse inicialmente um psicodiagnóstico, procurando entender os motivos que levavam aqueles adolescentes ao uso de drogas. Após este estudo um plano de tratamento era proposto, de acordo com a avaliação diagnóstica prévia. Seguia-se, então, a psicoterapia do caso.

O que se destacou para o autor como enigmático nesta prática clínica foi a dificuldade de se chegar a um único diagnóstico daqueles adolescentes. Mais precisamente, observava-se que eles se enquadravam simultaneamente em vários diagnósticos, apresentando-se ora como neuróticos, ora perversos, ora psicóticos, ora normais. Interrogou-se, então: como explicar esta simultaneidade dos diversos componentes psicopatológicos destes adolescentes usuários de drogas? Decorreriam tais componentes da adolescência pela qual passavam? Ou decorreria do uso de drogas? Dever-se-ia pensar tais adolescentes usuários de drogas como casos borderline?

O autor dirigiu-se a uma formação de mestrado em psicologia com a pretensão de realizar uma pesquisa visando a uma dissertação de mestrado que discutisse tais questões oriundas da clínica destes adolescentes usuários de drogas atendidos no SLA. Este mestrado foi realizado na Fundação Getúlio Vargas, Instituto Superior de Estudos e Pesquisas Psicossociais, Centro de Pós-Graduação em Psicologia, no Rio de Janeiro, e estendeu-se ao longo do período de agosto de 1980 até a data da defesa da dissertação de mestrado, em maio de 1983

Na revisão de literatura realizada com a finalidade de escrever a dissertação e discutir as questões clínicas acima destacadas, duas tendências teóricas opostas chamaram a atenção do autor. Foram elas: 1) a teorização da toxicomania em sentido restrito, isto é, da toxicomania da droga ou substância química. Esta tendência era representada principalmente por Olievenstein (1982, 1991), que concebera o estádio do espelho partido como uma suposta etapa do desenvolvimento psíquico infantil pela qual passa a criança candidata a, no futuro, tornar-se toxicômana caso venha a encontrar-se com a droga. Esta teorização era inspirada na concepção psicanalítica de Lacan (1966b, 1966/1998b) sobre o estádio do espelho como etapa do desenvolvimento psíquico infantil responsável pela função do "eu"de um indivíduo "normal"; e 2) as teorizações da toxicomania em sentido amplo, isto é, da toxicomania sem droga, realizadas principalmente por autores da psicanálise, abordando as toxicomanias como situadas além da substância química - independentes, então, do encontro do indivíduo com a droga.

Para detalhar um pouco mais estas duas tendências na teorização das toxicomanias, caberia começar enfatizando que a primeira tendência, conforme já discutido em Bento (1983, 1986a, 1986b, 1987, 1992a), é representada principalmente por Olievenstein $(1983,1991)$, autor que afirma que não existe toxicomania sem droga. Ele parece acreditar na existência de uma relação causal 
entre a ocorrência de certas experiências psíquicas na infância e o posterior surgimento de uma toxicomania. É o mesmo que dizer que ele admite a existência de uma etiologia psicológica desta doença, de um determinismo causal das toxicomanias. Ele postula de fato que o toxicômano passa por certas experiências na infância que seriam as "possíveis" responsáveis por seu posterior comportamento de se drogar. O termo "possíveis" foi colocado entre aspas para que, assim, se pudesse destacar a relatividade desta afirmação, pois Olievenstein $(1983,1991)$ crê que a existência de uma estrutura psíquica toxicomaníaca não garantirá necessariamente a produção de um toxicômano. Para que isto venha a ocorrer, o autor destaca duas condições necessárias e suficientes: 1) que o indivíduo encontre a droga; e 2) que ele possua certa relação com a transgressão da lei, ou, mais precisamente, uma tendência para transgredir a lei do pai.

É para explicar melhor a natureza desta estrutura psíquica toxicomaníaca que Olievenstein $(1983,1991)$ propõe a sua teorização sobre o estádio do espelho partido. Este autor explica que, na teorização sobre o estádio do espelho, Lacan considera que a formação da identidade ocorre quando a criança se descobre no espeIho como alguém separado da mãe. Neste momento se daria a ruptura da existência fusional mãe-criança. Olievenstein $(1983,1991)$ esclarece que psicótico seria aquele que, por inúmeras razões, permaneceu em estado fusional com a mãe porque não conseguiu ultrapassar o estádio do espelho. Com a criança candidata a uma futura toxicomania ocorreria algo de intermediário entre um estádio de espelho bem sucedido e um estádio de espelho impossível, isto é, algo entre uma passagem "normal" e outra "psicótica" por este estádio, ou, melhor ainda, simultaneamente uma saída normal e uma impossibilidade de saída ou passagem psicótica pelo mesmo estádio.

Mais precisamente, Olievenstein $(1983,1991)$ explica o estádio do espelho partido de uma criança candidata a uma futura toxicomania da seguinte maneira: no momento em que ela está diante do espelho, este se parte, passando a refletir simultaneamente uma imagem e uma fenda. Forma-se, então, uma imagem fragmentada, incompleta. Este autor diz que as fendas deixadas pelas ausências de espelho remetem àquilo que existia anteriormente a um espelho bem sucedido: a fusão mãe-filho, a indiferenciação, a inexistência de uma identidade. Admite então o mesmo autor que a vertente melancólica da toxicomania caracteriza-se por esta angústia de ser (nas imagens refletidas no espelho intacto) e, ao mesmo tempo, não ser (nas fendas do espelho partido), bem como pelo sentimento de incompletude que surge deste duplo movimento simultâneo do reconhecimento do eu no espelho e da falta deste reconhecimento nas fendas do espelho partido.

Avançando, Olievenstein $(1983,1991)$ diz que este estádio do espelho partido explica a incompletude, a existência parcial do toxicômano, o fato de ele não poder ser enquadrado inteiramente em nenhum diagnóstico, muito embora apresente um pouco de cada um deles. É neste sentido que este paciente será um pouco psicótico, um pouco maníaco-depressivo, um pouco perverso, um pouco homossexual etc. Entretanto, apenas um pouco, mas não inteiramente.

Caberia, então, interrogar: porque o espelho se parte na estruturação psíquica da criança candidata a uma futura toxicomania? Olievenstein $(1983,1991)$ responde a esta questão destacando a cinética da relação mãe-filho, sem a participação do pai. Mais precisamente, o autor diz que, quando o genitor encontra-se ausente, ou presente de forma negativa (pai frágil) na medida em que não se mostra suficientemente forte para romper o intercâmbio mãe-filho, resta à criança entregar-se à busca do prazer total e imediato simbolizado pela relação com sua genitora. Segundo o mesmo autor, nesta cinética mãe-filho sem a participação do pai, ou com sua participação precária, talvez se situe também a causa da homossexualidade tão frequente entre toxicômanos.

Na teorização lacaniana a lei é transmitida pelo pai. A propósito disto, Olievenstein $(1983,1991)$ diz que quando o genitor é vivenciado como frágil (pai idoso, impotente, homossexual ou incapaz de levar a mãe ao orgasmo), tal transmissão torna-se inoperante, surgindo a referida tendência para transgredir a lei, destacada acima como uma das duas condições necessárias e suficientes para a produção da toxicomania.

Esta tendência para transgredir a lei do pai conduz o indivíduo ao chamado "estádio do exagero", que sucede o estádio do espelho partido. Quando o pai não exerce sua função de transmitir a lei, o limite, o "não", e a necessidade da criança desta função paternal não pode 
ser verbalizada em virtude de alguma censura, é então comunicada por via não verbal, isto é, através de atuações - componente perverso das toxicomanias sob a forma do exagero e algum ato ou comportamento. Este exagero constitui, então, uma atuação na medida em que, ao ultrapassar o limite aceitável, o indivíduo expressa não verbalmente - pela via do ato ou, mais precisamente, do comportamento excessivo - um pedido de limites, comunicando, assim, sua carência da função paterna.

Na medida em que o exagero só aparece em virtude de algo que não é verbalizado (o pedido de limite), ele pressupõe a existência de um segredo. Segundo Olievenstein $(1983,1991)$ isto explica o prazer do toxicômano em fazer questão de tornar evidente e notório, especialmente para os familiares, seu comportamento exagerado de se drogar. Este autor cita um paciente de 35 anos que tentou suicídio por três vezes diante de seu filho e outro de 31 anos que produziu uma dúzia de comas também na frente do filho, ao passo que na ausência deste fizera apenas dois. A comunicação pela via da demonstração (via comportamental, via do exagero no ato de se drogar) de que algo vai mal passa a ocupar o lugar da verbalização de alguma falta, de algum mal.

Olievenstein postula que o exagero pode ter três momentos, a saber: 1) exagero da função lúdica; 2) exagero da masturbação; e 3) exagero do uso de droga, caso o indivíduo encontre a substância química e, assim, produza seu quadro clínico toxicomaníaco.

Para concluir, pode-se dizer que esta primeira tendência de abordagem das toxicomanias representada pela teorização do estádio do espelho partido por Olievenstein $(1983,1991)$ permitiu, na ocasião do primeiro tempo da experiência profissional clínica do autor deste trabalho, responder e embasar o principal questionamento clínico acima mencionado: sobre a simultaneidade dos diversos componentes psicopatológicos das toxicomanias, tese esta sustentada por Olievenstein e observada na clínica dos adolescentes usuários de droga atendidos pelo autor deste trabalho no SLA do Juizado de Menores do Rio de Janeiro.

Cabe agora passar ao detalhamento um pouco maior da segunda das duas tendências de teorização das toxicomanias acima mencionadas, a saber, aquela realizada pelos autores da psicanálise que abordam as toxicomanias como situadas além da substância química, independentes, então, do encontro do indivíduo com a droga. Conforme já discutido em Bento (1983, 1986a), entre os autores representantes desta tendência que aborda as toxicomanias em sentido amplo, destacam-se os seguintes:

Fenichel (1945/1981) foi o primeiro a introduzir o que se pode entender como a noção de"toxicomania sem droga" quando, no capítulo consagrado à abordagem das "perversões e neuroses impulsivas", destacou a oposição de dois subitens assim denominados: "adicção a drogas" (p.350) e"adicção sem drogas" (p.354) - toxicomanias sem drogas.

Martinez-Pina (1963) utilizou este sentido amplo das toxicomanias quando destacou o termo alemão sucht (adicção) para se referir a um estado patológico produtor de um forte desejo por alguma coisa, levando o indivíduo a permanecer preso a alguma determinada intenção, sem conseguir saciar-se. Este autor coloca que este termo designa um desvio de todos os interesses do indivíduo para um único objeto de desejo (a droga, o jogo, o poder, o dinheiro ou mesmo a paixão), que passa a ser investido com obsessão, paixão, exclusividade e de forma excessiva e desmedida. O autor resume suas ideias escrevendo: "O suchté como o vício da paixão" (p. 270).

Savitt (1966) descreveu o caso de um paciente homossexual como um adicto do sexo. O autor relatou que este paciente passava as tardes passeando pelas ruas em busca de um homem portador de um grande pênis, enquanto, à noite, ia para saunas homossexuais onde, em seu furor sexual, trocava um parceiro por outro com a finalidade de se colocar como objeto de felação. Não conseguia obter gratificação orgásmica e apenas interrompia estes atos quando começava a correr sangue de seu pênis.

Rosenfeld $(1972,1974)$ abordou a questão do uso do psicanalista como se ele fosse uma droga indispensável. Segundo este autor, a evolução do tratamento do toxicômano conduziria a uma aproximação mais objetiva do terapeuta, que deixaria de funcionar como droga, passando a ser percebido como pessoa. O autor destacou também aquilo que chamou de "equivalentes da adicção" para se referir à persistência de certos hábitos, após muitos anos de tratamento, como, por exemplo, predileções por determinadas comidas ou bebidas. Tais 
predileções passariam a ocupar o lugar dos antigos vícios, apresentando-se como uma atração muito forte por certos objetos vivenciados como imprescindíveis. Como exemplo, o autor citou a voracidade para trabaIhar, isto é, para realizar todo e qualquer tipo de tarefa.

Garzoli (1981) relacionou a adicção à transferência, relatando o caso de uma paciente que paralisou seu processo analítico quando começou a trazer uma série de sonhos fascinantes, não para elaborá-los, mas para consumir interpretações. Portanto, atuava no sentido de levar o analista a atuar no papel de um peito que provia infinitamente o"leite-interpretação", o que significava uma atuação na transferência de um estado de dependência total e exclusiva.

Kornblit (1981) diagnosticou uma família na qual o avô paterno é descrito como um adicto ao trabalho. Charles-Nicolas e Valleur $(1983,1991)$ abordaram a toxicomania como conduta ordálica e como paixão em sentido amplo. Finalmente, Ingold $(1983,1991)$ comparou a toxicomania com a paixão amorosa e com a paixão de Narciso do mito por si mesmo.

Para concluir, pode-se dizer que esta segunda tendência de abordagem das toxicomanias em sentido amplo, situadas além da substância química, independentes, então, do encontro do indivíduo com a droga, embora atraindo a atenção do autor deste trabalho por ocasião do primeiro tempo de sua história profissional, pouco acrescentou neste momento, vindo a ocupar lugar de maior destaque nos momentos seguintes, conforme se verá nos próximos itens, que abordarão respectivamente o segundo e o terceiro tempos desta história. Aliás, não é de se estranhar que, no primeiro tempo, as questões clínicas deste autor giravam em torno do diagnóstico de adolescentes usuários de droga (substância química) atendidos no SLA, sendo mesmo secundária a questão da noção de toxicomanias sem droga, em seu sentido amplo associada, em geral, ao termo "adicção".

\section{$2^{\circ}$ tempo}

Em fevereiro de 1984 o autor mudou-se do Rio de Janeiro para Curitiba para iniciar sua carreira como docente no Departamento de Psicologia de Universidade Federal do Paraná (UFPR). Enquanto professor passou a coordenar atividades de extensão universitária e a supervisionar alunos na prática da psicologia clínica, particularmente no atendimento de pacientes sofrendo de compulsões diversas: adicção a drogas, álcool, comida, consumo, sexo, relacionamentos amorosos "tóxicos" etc. Como professor, o autor passou a lecionar, dentre outras, a disciplina de nome "Psicanálise das Toxicomanias", procurando integrar as duas tendências destacadas acima no relato do primeiro tempo de sua história profissional, abordando, então, as toxicomanias da droga (substância química) juntamente com as toxicomanias sem droga.

Este segundo tempo da experiência profissional clínica do autor relacionada à hipótese das paixões tóxicas e à sua clínica estendeu-se de fevereiro de 1984 a junho de 1991. Neste tempo, esta hipótese em sua expressão final - que faz referência à existência de uma analogia funcional entre as paixões e as toxicomanias também não existia, estando, portanto, ainda em seu momento latente de concepção e gestação.

O grande destaque deste segundo tempo foi a utilização de filmes sobre relacionamentos amorosos "tóxicos" para servir de ilustração clínica nos cursos teóricos sobre Psicanálise das Toxicomanias realizados pelo autor. Em particular, dois filmes eram bastante utilizados: 1) Quando um homem ama uma mulher; e 2) Eu sei que vou te amar. Este último, baseado no livro de Jabor (1986) de mesmo nome, chegou mesmo a ser objeto de uma publicação em Bento (1991), na qual se analisam os diversos componentes psicopatológicos da toxicomania do amor e do sexo do casal de enamorados em destaque neste filme.

Outra publicação escrita neste segundo tempo, embora publicada apenas no terceiro tempo, abordando também a toxicomania sem droga, particularmente a toxicomania da paixão, pode ser aqui citada para ilustrar a produção do autor neste segundo momento (Bento, 1992b).

Em resumo, a hipótese central do primeiro tempo relacionada à clínica de adolescentes usuários de droga - aquela dos diversos componentes psicopatológicos das toxicomanias - foi, neste segundo tempo, generalizada às toxicomanias sem droga, dando destaque, entre estas, à clínica das toxicomanias do amor e do sexo. 


\section{$3^{\circ}$ tempo}

No período compreendido entre julho de 1991 e fevereiro de 1996 o autor deste trabalho recebeu uma licença do Ministério da Educação e Cultura do Brasil (MEC) e da UFPR para fazer doutorado em Psicopatologia Fundamental e Psicanálise na França, na Universidade Paris 7. Iniciou sua licença fazendo um estágio de aproximadamente dois meses no Centre Médical Marmottan, Paris, um centro para desintoxicação de toxicômanos em regime de internação, naquela ocasião sob a direção de Claude Olievenstein. O terceiro tempo da experiência profissional clínica deste autor relacionada à hipótese das paixões "tóxicas" e à sua clínica se estendeu, então, ao longo dos meses de julho e agosto de 1991.

Em seguida, iniciou-se uma pesquisa de revisão de literatura sobre o tema "Psicanálise e Toxicomanias" visando à futura tese de doutorado, essencialmente teórica, a ser defendida na Universidade Paris 7. Após um ano desta atividade de exame da literatura francesa sobre o referido tema, o autor ficou marcado particularmente pela leitura de dois textos principais, a saber: Delrieu (1988) e Le Poulichet (1987). Foram estes dois autores e seus escritos que forneceram os subsidios teóricos para que o autor analisasse criticamente sua experiência ao longo do primeiro e do segundo tempo de sua história profissional relacionada à hipótese das paixões tóxicas e à sua clínica, levando-o à formulação final e explícita, bem como ao nascimento desta hipótese que faz referência à existência de uma analogia funcional entre as paixões e as toxicomanias, estruturando seu projeto de tese de doutorado e, finalmente, marcando com um diferencial significativo de mudança o terceiro tempo de sua história profissional e a sua compreensão da noção de toxicomania. Seguem, então, os resumos destes achados teóricos em Delrieu (1988) e em Le Poulichet (1987), após introduzi-los com um breve resumo de Bento (1999) discursando sobre o aparecimento da noção de toxicomania no final do século XIX:

Enquanto que o uso de 'drogas' remonta à Antiguidade, é apenas por volta do final do século XIX que aparece a noção de 'toxicomania', tal como ela é concebida atualmente como associada à imagem de um flagelo social, à ideia de doença e ao domínio médico.

Mais precisamente, esta noção de toxicomania como 114 e por abuso de droga aparece pela primeira vez em 1875 com o alemão Édouard Levinstein, sob o nome de morfiomania (Bento, 1999, p.16 - tradução livre).

Quanto aos achados teóricos em Delrieu (1988), cabe destacar que este autor examina mais de quatrocentos textos, estendendo-se sobre quase dois séculos (1800-1960) para construir uma história da moderna"toxicomania" na França. Ele mostra que o termo nasce no campo médico, no fim do século XIX, associado aos sentidos de "degenerescência", "imoralidade" e "paixão", assim discorrendo:

Considerado como um degenerado, logo como alguém atingido em suas faculdades superiores, particularmente morais, o toxicômano, nestes anos 1871-1898, cai sob o golpe destes tipos de julgamento: é um "viciado", ou um "perverso". com efeito, se é desagradável, para o mundo médico muito afetado por esta paixão, tomar para si tais qualificativos, por outro lado isto agrada àqueles que querem controlar o que alteraria as forças vivas da nação (trabaIhadores, soldados, funcionários coloniais). Aqui o ideólogo toma a frente do terapeuta (Delrieu, 1988, p.39 - tradução livre).

Caberia ainda citar o pai da moderna toxicomania, Édouard Levinstein, em quem se nota o destaque do sentido passional do termo, quando ele escreve sobre o mesmo através de sua abordagem da morfiomania: “... morfiomania significa a paixão que possui um indivíduo de se servir da morfina como excitante ou como alimento, e o estado patológico que resulta do uso abusivo deste medicamento" (Levinstein, 1878, p.3 - tradução livre).

Quanto aos achados teóricos em Le Poulichet (1987), cabe destacar que esta autora abre seu livro com um primeiro capítulo crítico que funciona como introdução daquilo que ela diz pretender enquanto proposta rigorosa de teorização psicanalítica no campo das toxicomanias - que aparece apenas no seu segundo capítulo. Significa dizer que a autora tem a preocupação de abrir sua obra com um primeiro capítulo que analisa criticamente as propostas existentes na literatura versando sobre este campo de teorização para, assim, justificar sua proposição no mesmo campo; esta proposição apenas se faz presente no segundo capítulo. Em sua crítica, esta autora denuncia a inadequação de certas teorias sobre as toxicomanias que, ainda que se pretendam psicanalíticas, colocam a ênfase na substância 
tóxica e no comportamento de se drogar (com a ingestão de substâncias químicas), esquecendo, assim, que em psicanálise a essência de toda pesquisa deveria ser a busca do sujeito do inconsciente. Em sua preocupação de propor uma teorização rigorosa neste domínio, a autora evoca o contexto de aparição do termo "toxicomania" (no século XIX, quando ele estava associado aos sentidos de doença, de flagelo social e, também, de paixão), deplora a perda desta última acepção (toxicomania como paixão) no campo da reflexão psicanalítica sobre as toxicomanias e termina propondo o que ela chama de operação do phármakon, uma operação situada além da toxicomania (da droga ou substância química).

A inspiração inicial de Le Poulichet (1987) ao propor a operação do phármakon é o phármakon platônico descrito por Derrida $(1995,1997)$ em “A farmácia de Platão" como veneno e remédio, simultaneamente e paradoxalmente, ou droga maléfica e benéfica, filtro de esquecimento e possibilidade de salvação pelo acesso ao lógos. Le Poulichet (1987) abre seu livro citando como epígrafe uma passagem de Derrida sobre este phármakon platônico, na qual se pode observar seu sentido paradoxal. Derrida (1997) escreve a esse respeito:

... E passa-se então ao diálogo sobre a essência da sabedoria, o melhor phármakon, o remédio capital.

A filosofia opõe, pois, ao seu outro, essa transmutação da droga em remédio, do veneno em contraveneno. Uma tal operação não seria possível se o phármako-lógos não abrigasse nele mesmo essa cumplicidade dos valores contrários, e se o phármakon em geral não fosse, antes de toda discriminação, o que, dando-se como remédio, pode [se] corromper em veneno, ou o que se dando como veneno pode se verificar remédio, pode aparecer depois de administrado em sua verdade de remédio. A "essência" do phármakon é que, não tendo essência estável, nem caráter "próprio", não é, em nenhum sentido dessa palavra (metafísico, físico, químico, alquímico), uma substância. O phármakon não tem nenhuma identidade ideal, ele é aneidético, e primeiro porque ele não é monoeidético (no sentido em que o Fédon fala do eîdos como de um simples: monoeidés). Esta "medicina" não é um simples. ...

Esta não-substância farmacêutica não se deixa manejar com toda segurança nem em seu ser, já que ela não o tem, nem em seus efeitos, que podem incessantemente mudar de sentido. Assim, a escritura, anunciada por Theuth como um remédio, como uma droga benéfica, é em seguida devolvida e denunciada pelo rei, depois, no lugar do rei, por Sócrates, como substância maléfica e filtro do esquecimento. Inversamente, e ainda que a legibilidade não seja imediata, a cicuta, essa poção que nunca teve outro nome no Fédon senão o de phármakon, é apresentada a Sócrates como um veneno, mas ela se transforma, pelo efeito do lógos socrático e pela demonstração filosófica do Fédon, em meio de libertação, possibilidade de salvação e virtude catártica. A cicuta tem um efeito ontológico: iniciar à contemplação do eîdos e à imortalidade da alma. Sócrates a toma como tal. (pp.73) - Ver passagem correspondente na edição francesa: Derrida (1968/1995, p.333).

Este phármakon platônico, destacado nesta passagem de Derrida como uma "não substância farmacêutica" paradoxal, ao mesmo tempo veneno e remédio, não poderia ser comparado ou assimilado à "paixão", já que esta é igualmente uma não substância e também comporta um sentido paradoxal desde a origem deste termo na Antiguidade Grega, conforme já se analisou em Bento (2006a, 2008)?

Sobre a operação do phármakon, Le Poulichet (1987) também a situa além da substância química. Em outras palavras, tanto a operação do phármakon quanto o phármakon platônico evocam a ideia da existência de uma não substância na base da intoxicação, de uma toxicomania sem droga ou substância química. A respeito desta operação do phármakon, situada além da droga, Le Poulichet (1987) escreve:

... tentarei num primeiro tempo especificar as qualidades desta operação, me afastando dos modelos psicofarmacológicos. É apenas após ter apreciado as características desta operação do phármakon - que não é equivalente ao uso de drogas - que eu examinarei o tipo de formação ao qual ela pertence. Apenas neste momento eu abordarei o lugar desta formação nas diferentes toxicomanias (p.39 tradução livre).

Pode-se já pressentir que o verdadeiro tóxico - aquele que nos ocupa numa clínica psicanalítica - não é provavelmente a droga em si! (p.73 tradução livre).

Para precisar o que seria esta não substância, que está além da droga, na base da intoxicação, ou mais precisamente, da operação do phármakon, Le Poulichet não a compara com a paixão, conforme foi questionado acima. No entanto, ao criticar as teorias de 
inspiração psicanalítica sobre as toxicomanias influenciadas pelo modelo positivista de ciência conduz o leitor à compreensão de que tais teorias têm valorizado o exterior, o que é objetivamente observável: a substância química e o comportamento de se autoadministrar tal substância, esquecendo-se, assim, do interior, do inconsciente, de refletir o que seria a intoxicação de um ponto de vista verdadeiramente psicanalítico, valorizando o subjetivo. É neste momento que a autora evoca a figura plural da "paixão", presente nas primeiras definições médicas na origem das modernas toxicomanias do final do século XIX, deplorando o esquecimento desta imagem por parte das atuais abordagens psicanalíticas das toxicomanias. Le Poulichet (1987 p.13) escreve a esse respeito:

... Precisamente, uma certa psicanálise pode validar esta dupla empreitada de medicalização e psicologização das toxicomanias. A figura plural da 'paixão', que dominava no século XIX para dar conta das toxicomanias e que não separava o corpo da 'alma', teria constituído uma base mais propícia à reflexão psicanalítica, conservando a dimensão subjetiva e enigmática da experiência (tradução livre).

Foi com a finalidade de trazer uma teorização rigorosa em psicanálise das toxicomanias que a autora propôs a operação do phármakon. Esta operação investiria também em uma não substância que, como já foi assinalado, Le Poulichet não refere como sendo a paixão, mas sim, o excesso narcísico, um investimento que remeteria a uma autoconservação paradoxal.

Prosseguindo, Le Poulichet afirma que tanto a toxicomania que investe nas substâncias químicas quanto a operação do phármakon em torno da não substância procuram uma saída pelo excesso narcísico, um retorno ao órgão, ao corpo real, no lugar de um investimento simbólico, como alternativa para se lidar com uma excitação, uma angústia, um vazio devido à separação do objeto do mundo exterior e, também, uma ausência de palavras para lidar com tal angústia de separação. Le Poulichet (1987) escreve:

... E é bem uma forma de angústia que aparece quando falta o tóxico, como se o corpo, no lugar de se formar nas cadeias significantes, chamasse a restituição de um órgão que "liga" as excitações. Estas últimas suscitam uma Hilflosigkeit que testemunha um aumento intolerável das tensões. É aliás frequente como em resposta às formas de vazios (arrom- bamentos) que "recaídas" intervêm neste tempo da abstinência. O tóxico ressurge como que para restaurar uma proteção face aos acontecimentos ou pensamentos frequentemente sentidos como ameaçadores, próprios a despertar o terror e o pavor.

mas este modelo do vazio parece representar uma constante clínica quando o uso de tóxicos se transformou numa operação do phármakon.

Como se pode conceber este vazio (arrombamento)? Ele parece adquirir uma forma de inteligibilidade se ele se acha remetido ao "reduplicamento narcísico" que a operação do phármakon organiza. Nenhum desses vazios sobrevêm precisamente, quando se realiza uma tal operação. E é bem muito frequentemente uma espécie de meio-sono que o phármakon provoca, criando como que um retraimento dos investimentos do mundo exterior. Um tal "reduplicamento narcísico", que tenta "ligar" as excitações, marca o fracasso de uma ligação mais estruturante: de fato, a noção freudiana de vazio implica aqui numa falha da ancoragem do corpo nas cadeias significantes (p.46, tradução livre).

Pela passagem acima observa-se que, em Le Poulichet, a não substância que intoxica na operação do phármakon é o excesso narcísico, um reduplicamento do narcisismo a partir da retirada dos investimentos nos objetos do mundo exterior. Mais precisamente, pode-se dizer que a proposta rigorosa de teorização psicanalítica das toxicomanias desta autora afirma que o que intoxica, do ponto de vista do inconsciente, é o excesso narcísico.

Partindo destes achados de Le Poulichet (1987) para repensar criticamente a história profissional clínica do autor relacionada à hipótese das paixões "tóxicas", pode-se dizer que a ideia de "toxicomania sem droga"já Ihe era conhecida desde o primeiro tempo desta sua história, conforme se relatou acima. No entanto, ao ler estas críticas de Le Poulichet (1987) o autor se deu conta de que, apesar de sempre ter estado em busca de uma teorização psicanalítica rigorosa tratando das toxicomanias, havia até o momento valorizado o comportamento toxicomaníaco em detrimento da valorização do sujeito do inconsciente, este enquanto objeto essencial de uma teorização psicanalítica rigorosa. Era este comportamento toxicomaníaco que era valorizado tanto quando utilizava expressões como "toxicomania 
do amor, do sexo e da paixão"(Bento, 1991; 1992b), quanto quando defendia a tese dos diversos componentes psicopatológicos das toxicomanias (Bento, 1983; 1986a; 1986b; 1987; 1991; 1992a).

Embora Le Poulichet (1987) não tenha feito uma crítica diretamente a Olievenstein, nem, obviamente, ao seu estádio do espelho partido, pode-se inferir, a partir da leitura da primeira, que a proposta do segundo é inadequada, pois a teorização de Olievenstein (1983; 1991) sobre este estádio do espelho partido expressa uma pretensão psicanalítica, já que se inspira no estádio do espelho de Lacan (1966b, 1966/1998b), mas, ao mesmo tempo, mistura a noção de estrutura da psicanálise com a valorização do sintoma-comportamento própria das psicologias comportamentais. Mais precisamente, Olievenstein defende a ideia de uma estrutura borderline para explicar os diversos componentes psicopatológicos das toxicomanias, os quais, na verdade, constituem sintomas, comportamentos patológicos. Como se sabe, a noção de borderline tem sido muito criticada pelos psicanalistas rigorosos que acreditam na existência de uma única estrutura e não um conjunto de diversas estruturas reunidas e presentes simultaneamente em um único caso. Sobre esta crítica à expressão e à ideia contida no termo "borderline", Laplanche e Pontalis (1967/1998) escrevem, ao abordá-lo através da expressão "caso-limite":

Expressão utilizada a maioria das vezes para designar afecções psicopatológicas situadas no limite entre neurose e psicose, particularmente esquizofrenias latentes que apresentam uma sintomatologia de feição neurótica.

Como se pode ver na passagem acima, a expressão "caso-limite" (borderline) não possui uma significação nosográfica rigorosa. Pode-se supor nas entrelinhas desta passagem que a falta de rigor desta expressão resulta da mistura da noção de estrutura utilizada na psicanálise com uma suposta noção de "sintoma-comportamento" utilizado com função defensiva, esta última noção muito comum em abordagens próprias de uma psicologia comportamental. Parece que, em se tratando de rigor de abordagem, não há problema algum em se optar por fazer psicologia do comportamento, desde que esta opção não apareça misturada com outras propostas que lhe sejam incompatíveis. Neste caso, parece que a falta de rigor residiria em misturar psicologia com- portamental com psicanálise, a primeira valorizando o estudo do comportamento, em oposição à segunda, que coloca a ênfase na investigação do sujeito do inconsciente. Obviamente, duas propostas nitidamente incompatíveis, dois objetos de estudos claramente distintos.

Na compreensão corrente da clínica psicanalítica das toxicomanias, sabe-se que existem toxicômanos com diversas estruturas, cada toxicômano portador de apenas uma das três estruturas psicopatológicas clássicas (ou neurótica, ou perversa, ou psicótica), embora todos podendo apresentar, com fins defensivos e simultaneamente, sintomas ou comportamentos patológicos próprios de uma ou mais e até das três estruturas.

A elaboração feita pelo autor após ler Le Poulichet (1987) levou-o a rever sua compreensão da noção de toxicomania e a estruturar um projeto de tese de doutorado coerente com o que havia assimilado principalmente desta autora e de Delrieu (1988). Reformulou, então, sua proposição anterior sobre a "toxicomania do amor, do sexo e da paixão", já que esta expressão sugeria um comportamento de se intoxicar respectivamente com o amor, com o sexo e com a paixão. No lugar desta ideia passou a adotar o método do raciocínio por analogia para pensar a relação existente entre os três termos que se apresentavam até então como relevantes, a saber: 1) paixão; 2) toxicomania; e 3) narcisismo. Mais precisamente, passou-se a partir do pressuposto hipotético de que a paixão era análoga à toxicomania porque existiria uma função semelhante, mas não idêntica, nas duas, que as aproximava: a função do narcisismo. Mais precisamente, passou-se a postular que, do ponto de vista do inconsciente, seria o excesso narcísico aquilo que intoxicaria tanto na paixão quanto na toxicomania. Neste momento nasceu a hipótese das paixões "tóxicas". Acreditou-se que com a substituição do modelo comportamental inerente à expressão "toxicomania do amor, do sexo e da paixão" por um método de pesquisa (o raciocínio por analogia), evocando a linguística no lugar da psicologia comportamental, seria possível valorizar mais a dimensão da experiência subjetiva inconsciente em detrimento da valorização da dimensão comportamental. Como se sabe, Lacan enuncia sua tese fundamental quando afirma que o inconsciente é estruturado como linguagem. Lacan (1966a, 1966/1998a) escreve a este respeito desde as primeiras 
linhas do subitem "A letra no inconsciente", na obra "A instância da letra no inconsciente ou a razão desde Freud":

A obra completa de Freud nos apresenta uma página de referências filológicas a cada três páginas, uma página de inferências lógicas a cada duas páginas e, por toda parte, uma apreensão dialética da experiência, vindo a analítica linguageira reforçar ainda mais suas proporções à medida que o inconsciente vai sendo mais diretamente implicado.

Assim é que, na Ciência dos sonhos, trata-se apenas, em todas as páginas, daquilo a que chamamos a letra do discurso, em sua textura, seus empregos e sua imanência na matéria em causa. Pois esse texto abre com sua obra a via régia para o inconsciente.

A primeira cláusula, articulada logo no capítulo preliminar, posto que a exposição não pode suportar sua demora, é que o sonho é um rébus.... As imagens do sonho só devem ser retidas por seu valor de significante, isto é, pelo que permitem soletrar do "provérbio" proposto pelo rébus do sonho. Essa estrutura de linguagem que possibilita a operação da leitura está no princípio da significância do sonho, da Traumdeutung (Lacan, 1966/1998a, p.513 Ver passagem correspondente na edição francesa: Lacan (1966a, p.509).

Lacan postula assim sua hipótese da estruturação do inconsciente enquanto linguagem sublinhando, ao mesmo tempo, que foi Freud quem primeiro propôs "uma apreensão dialética da experiência, vindo a analítica linguageira reforçar ainda mais suas proporções à medida que o inconsciente vai sendo diretamente implicado."(1966/1998a, p. 513). Esta hipótese encontra seu fundamento mais forte na Interpretação de sonhos (Freud, 1900/1972a, 1900/1972b), sobretudo porque é a "ciência dos sonhos" que, abrindo "com sua obra a via régia para o inconsciente", demonstra, mais do que as outras obras de Freud, a existência de um inconsciente estruturado como linguagem.

Tendo justificado acima a escolha do raciocínio por analogia pelo fato de ele permitir maior rigor em uma pesquisa psicanalítica - em função de ser um método evocando a linguística e seu correspondente objeto (a língua), no lugar da psicologia do comportamento e seu respectivo objeto (o comportamento) - pode-se agora avançar esclarecendo que o projeto de pesquisa de tese de doutorado passou a ser direcionado pelo seguinte problema fundamental: de um ponto de vista metapsicológico (inconsciente), em particular, do ponto de vista da economia narcísica, não se poderia comparar a paixão e a toxicomania? Em outras palavras, existiria uma analogia fundamental entre a paixão e a toxicomania a partir da função do narcisismo, mais precisamente do excesso narcísico, semelhante na paixão e na toxicomania? Com tais questões esboçava-se, então, a hipótese fundamental deste trabalho - a das paixões "tóxicas", assim expressa: existe uma analogia funcional entre as paixões e as toxicomanias a partir da função do excesso narcísico, semelhante, porém não idêntica, nas paixões e nas toxicomanias.

Equacionado o problema de pesquisa na forma acima mencionada, o plano da tese estava implicitamente definido. Seu objetivo seria encontrar os fundamentos teóricos destas três noções articuladas conforme se descreveu acima tanto o problema quanto a hipótese central das paixões "tóxicas". A tese, essencialmente teórica, seria então dividida em três grandes partes, cada qual consagrada ao estudo de uma destas três noções em destaque, a saber: 1) paixão; 2) toxicomania; e 3) narcisismo, bem como ao estudo das mútuas relações analógicas entre as mesmas noções. Acreditou-se que mediante este plano seria possível construir um corpo teórico e discutir os fundamentos teóricos da hipótese central, a partir de uma perspectiva rigorosamente psicanalítica de teorização sobre as toxicomanias, as adicções e, finalmente, as paixões "tóxicas".

\section{Considerações Finais}

Acredita-se que este estudo atingiu seu objetivo principal, pois, de fato, foram apresentadas aqui as justificativas clínicas e teóricas da hipótese das paixões "tóxicas" a partir de uma dupla empreitada: 1) o relato e o questionamento da história da experiência profissional do autor com a clínica psicológica das paixões "tóxicas", ao longo de três tempos principais (de 1/78 a 2/84; de 2/84 a 6/91; a partir de 7/91); e 2) a abordagem dos fundamentos teóricos que embasaram cada um destes três momentos. Com esta dupla ação foi possível demonstrar como se chegou à hipótese em questão e, assim, justificá-la com argumentos clínicos e teóricos.

Quanto às limitações deste estudo, pode-se dizer que não se abordou a discussão dos fundamentos teóri- 
cos dos métodos desta pesquisa, nem as aplicações destes métodos nas paixões "tóxicas", até porque estes não faziam parte dos objetivos e, também, porque tal empreitada extrapolaria os limites espaciais deste trabalho. Para os leitores interessados em se aprofundar nestes fundamentos, particularmente nas bases teóricas do método do raciocínio por analogia, bem como no estudo de suas relações com o método semiológico, ambos métodos centrais nesta pesquisa das paixões "tóxicas", sugere-se a leitura de Bento (1996).

No que concerne especificamente aos fundamentos teóricos do método semiológico utilizado nesta investigação das paixões "tóxicas", deve-se informar que estes já foram discutidos em outras oportunidades, podendo-se, então, remeter os leitores interessados à leitura de Bento (1996, 2006b, 2007a, 2007b).

Já os leitores interessados em se aprofundar na pesquisa das aplicações do método semiológico no campo das toxicomanias, das adicções e das paixões "tóxicas", com ênfase na discussão da hipótese central das paixões "tóxicas" tal como enunciada neste estudo, poderão ler Bento (1993, 1994a, 1994b, 1995, 1996, 1998, 1999, 2003, 2006a, 2007c, 2008).

\section{Referências}

Bento, V. E. S. (1983). Os componentes psicopatológicos das toxicomanias. Dissertação de mestrado não-publicada, Centro de Pós-Graduação em Psicologia, Fundação Getúlio Vargas, Rio de Janeiro.

Bento, V. E. S. (1984). A psicologia no Serviço de Liberdade Assistida do Juizado de Menores da comarca do Rio de Janeiro. In F. A. M. Rosa (Org.), Direito e mudança social (pp.189-199). Rio de Janeiro: OAB-RJ.

Bento, V. E. S. (1986a). Os componentes psicopatológicos das toxicomanias. Curitiba: Edição do Autor.

Bento, V. E. S. (1986b). O paradoxo da vivência de morte do toxicômano. Arquivos Brasileiros de Psicologia, 38 (1), 47-57.

Bento, V. E. S. (1987). A psicopatologia da drogadicção: uma abordagem psicanalítica. Arquivos Brasileiros de Psicologia, $39(1), 41-50$

Bento, V. E. S. (1991). Sexualidade das toxicomanias do amor e do sexo como controle e poder onipotentes: uma abordagem psicanalítica e uma análise do filme "Eu sei que vou te amar". Jornal Brasileiro de Psiquiatria, 40 (9), 451-456.

Bento, V. E. S. (1992a). Psychopathologie psychanalytique des toxicomanies. Interventions: Revue del'ANIT-Association Nationale des Intervenants en Toxicomanie, (34), 35-40.
Bento, V. E. S. (1992b). A "Psicologia de grupo e a análise do ego (1921)" de Freud e uma introdução à psicanálise da toxicomania da paixão em Freud. Documenta CRP-08, 2 (3), 109-124.

Bento, V. E. S. (1993). Tóxico, droga, toxicomania e adicção: uma introdução à etimologia segundo uma ótica psicanalítica. Jornal Brasileiro de Psiquiatria, 42 (7), 373-380.

Bento, V. E. S. (1994a). "Leonardo da Vinci e uma lembrança da sua infância": considerações sobre o narcisismo em Freud e sobre a paixão amorosa "tóxica" a partir de Freud. Temas: Teoria e Prática do Psiquiatra, 24 (47), 94-113.

Bento, V. E. S. (1994b). Três ensaios sobre a teoria da sexualidade: considerações sobre o conceito de narcisismo em Freud (1905) e sobre a paixão amorosa "tóxica" a partir de Freud. Revista ABP-APAL, 16 (4), 154-164.

Bento, V. E. S. (1995). O presidente Schreber, um caso de paranóia: considerações sobre o narcisismo em Freud (1911) e sobre a paixão amorosa "tóxica" a partir de Freud. Informação Psiquiátrica, 14 (1), 27-35.

Bento, V. E. S. (1996). La passion amoureuse "toxique": une approche psychanalytique à partir de la sémiologie et du narcissisme chez Freud. Thèse de doctorat pas-publié, Laboratoire de Psychopathologie Fondamentale et Psychanalyse, Université Paris 7. Paris, France.

Bento, V. E. S. (1998). O narcisismo em Freud e paixão "tóxica" a partir de Freud. Psicologia em Estudo, 3 (2), 1-37.

Bento, V. E. S. (1999). Pour introduire une "sémiologie psychanalytique" de la notion de "toxicomanie" dans I'approche médicale. Interventions: Revue de I'ANIT Association Nationale des Intervenants en Toxicomanie, (68), 16-22.

Bento, V. E. S. (2003). O narcisismo em Freud e a paixão "tóxica" a partir de Freud. In M. Baptista, M. S. Cruz \& R. Matias (Orgs.), Drogas e pós-modernidade: prazer, sofrimento e tabu (Vol. 1, pp.147-172). Rio de Janeiro: EdUERJ.

Bento, V. E. S. (2006a). Tóxico e adicção comparados a paixão e toxicomania: etimologia e psicanálise. Psicologia USP, 17 (1), 181-206.

Bento, V. E. S. (2006b). Seria a semiologia de Saussure fundamento e justificativa para o método de pesquisa de revisão de literatura em psicanálise? Estudos de Psicologia (Campinas), 23 (4), 407-423.

Bento, V. E. S. (2007a). Totem e Tabu: uma "semiologia psicanalítica" em Freud? Estudos de Psicologia (Campinas), 24 (3), 397-406.

Bento, V.E. S. (2007b). Existiria uma "semiologia psicanalítica" em Lacan? Aletheia, (25), 177-190.

Bento, V. E. S. (2007c). Para uma semiologia psicanalítica das toxicomanias: adicções e paixões tóxicas no Freud pré-psicanalítico. Revista Mal-estar e Subjetividade, 7 (1), 89-121.

Bento, V. E. S. (2008). Para uma semiologia psicanalítica da paixão na Antiguidade Grega e seus sentidos adictivo e tóxico. Psicologia USP, 19 (2), 129-158.

Charles-Nicolas, A., \&Valleur, M. (1983). As condutas ordálicas. In C. Olievenstein. A vida do toxicômano (pp.87-105). Rio de Janeiro: Zahar. 
Charles-Nicolas, A., \& Valleur, M. (1991). Les conduits ordaliques. In C. Olievenstein. La vie du toxicomane (3e. éd., pp.82-99). Paris: PUF.

Delrieu, A. (1988). L'inconsistance de la toxicomanie. Analytica, Cahiers de Recherche du Champ Freudien, (53), $1-128$.

Derrida, J. (1995). La pharmacie de Platon. In Platon \& J. Derrida, Phèdre suivi de La pharmacie de Platon (pp. 255-403). Paris: GF-Flammarion.

Derrida, J. (1997). A farmácia de Platão (2a. ed.). São Paulo: Iluminuras.

Fenichel, O. (1981). Perversões e neuroses impulsivas. In O. Fenichel. Teoria psicanalítica das neuroses (pp.303-359). Rio de Janeiro: Atheneu

Freud, S. (1972a). A interpretação de sonhos (primeira parte). In S. Freud. Edição standard brasileira das obras psicológicas completas de Sigmund Freud (Vol. 4, pp.vii360). Rio de Janeiro: Imago.

Freud, S. (1972b). A interpretação de sonhos (segunda parte). In S. Freud. Edição standard brasileira das obras psicológicas completas de Sigmund Freud (Vol. 5, pp.361-663). Rio de Janeiro: Imago.

Garzoli, E. H. (1981). Sobre la adicción de transferencia. Psicoanalisis, 3 (1), 193-229.

Ingold, R. (1983). O estado de dependência. In C. Olievenstein. A vida do toxicômano (pp.51-73). Rio de Janeiro:Zahar.

Ingold, R. (1991). L'état de dépendance. In C. Olievenstein. La vie du toxicomane (3e. éd., pp.49-70). Paris: PUF.

Jabor, A. (1986). Eu sei que vou te amar (7a. ed). Rio de Janeiro: Record.

Kornblit, A. (1981). Puntuaciones semánticas en el análisis de las relaciones familiares. Revista Argentina de Psicologia, 12 (30), 157-182.

Lacan, J. (1966a). L'instance de la lettre dans l'inconscient ou la raison depuis Freud. In J. Lacan. Écrits (pp.493-528). Paris: Éditions du Seuil.

Lacan, J. (1966b). Le stade du miroir comme formateur de la fonction du Je telle qu'elle nous est révélée dans l'expérience psychanalytique. In J. Lacan. Écrits (pp.93-100). Paris: Éditions du Seuil.
Lacan, J. (1998a). A instância da letra no inconsciente ou a razão desde Freud. In J. Lacan. Escritos (p.496-533). Rio de Janeiro: Jorge Zahar. (Originalmente publicado em 1966)

Lacan, J. (1998b). O estádio do espelho como formador da função do eu tal como nos é revelada na experiência psicanalítica. In J. Lacan. Escritos (pp.96-103). Rio de Janeiro: Jorge Zahar. (Originalmente publicado em 1966)

Laplanche, J., \& Pontalis, J.-B. (1990). Vocabulaire de la psychanalyse (10e. éd.). Paris: PUF. (Originalement publié en 1967)

Laplanche, J., \& Pontalis, J.-B. (1998). Vocabulário da psicanálise (2a. ed., 8a. tiragem). São Paulo: Martins Fontes

Le Poulichet, S. (1987). Toxicomanies et psychanalyse: Les narcoses du désir. Paris: PUF.

Levinstein, E. (1878). La morphiomanie. Paris: Masson.

Martínez-Pina, A. (1963). Delimitation y analisis fenomenologico del concepto toxicofilia. Revista de Psiquiatría y Psicología Médica de Europay América Latina, 6 (4), 270-289.

Olievenstein, C. (1983). A infância do toxicômano. In C. Olievenstein. A vida do toxicômano (pp.7-36). Rio de Janeiro:Zahar.

Olievenstein, C. (1991). L'enfance du toxicomane. In C. Olievenstein. La vie du toxicomane (3e. éd., pp.5-33). Paris: PUF.

Rosenfeld, D. (1972). El paciente drogadicto: guía clínica y evolución psicopatológica en el tratamiento psicoanalítico. Revista de Psicoanalisis, 29 (1), 99-135.

Rosenfeld, D. (1974). Adicción a las drogas, omnipotencia narcisista, trastornos en la piel y esquema corporal. Aportes a la dialéctica de los grupos. Revista de Psicoanalisis, 31 (1-2), 365-402.

Savitt, R. A. (1966). Estudios psicoanalíticos sobre la adicción: la estructura del yo en la adicción a narcóticos. Revista de Psicoanalisis, 23 (3), 334-344.

Recebido em: 31/1/2009

Aprovado em: 26/5/2009 